\title{
Metamorphic Remobilization and Hydrothermal Superimposition Records in Sulfides from Archean VMS Deposit
}

\author{
FUDE ZHAO $^{1}$, FEI HUANG ${ }^{1}$, LEI CHEN ${ }^{2}$, WENYUAN \\ $\mathrm{GAO}^{1}$ AND LIN MENG ${ }^{1}$
}

${ }^{1}$ Key Laboratory of Ministry of Education on Safe Mining of Deep Metal Mines and School of Resources and Civil Engineering, Northeastern University, Shenyang, Liaoning

${ }^{2}$ MNR Key Laboratory of Metallogeny and Mineral Assessment, Institute of Mineral Resources, CAGS, Beijing

Presenting Author: zhaofude@stumail.neu.edu.cn

The Hongtoushan copper-zinc deposit, located in northeastern China, is a VMS deposit formed in Archean. It has experienced multiple geological processes and retains a large amount of information from Archean seafloor mineralization to metamorphic transformation and later hydrothermal superimposition. It is a typical complex deposit with multiple geneses.

To further study the enrichment mechanism of the deposit, massive and disseminated ore samples and surrounding rock samples adjacent orebody were collected from- 467 to -827 , a total of 7 mining levels, and mineral assembles and textural relationships were obtained using FE-SEM, the major and trace element of sulfide using EPMA and LA-ICP-MS, sulfur isotope characteristics using LA-(MC)-ICP-MS.

According to the mineral texture relationship, trace elements, and sulfur isotope characteristics, two stages of mineralization are identified: 1) metamorphic remobilization, early mineral texture features are obliterated, sulfide undergoes intense remobilization and recrystallization, mainly forming a mineral assemble of pyrite + sphalerite + pyrrhotite + chalcopyrite \pm magnetite; 2) hydrothermal superimposition, the intergranular gap is the main fluid channel, which formed by different minerals volume contraction during metamorphism, with the minerals assemble of pyrite + chalcopyrite + sphalerite.

The remobilization sequence of sulfide is chalcopyrite $>$ sphalerite $\approx$ pyrrhotite $>$ pyrite during the metamorphism. The trace elements of $\mathrm{Co}, \mathrm{Ni}, \mathrm{Se}$ in pyrite and $\mathrm{Fe}$ in sphalerite are not affected by metamorphism, which can constraint the initial mineralization temperature of the Hongtoushan deposit to $310-350^{\circ} \mathrm{C}$, and the sulfur activity $\alpha_{\mathrm{S} 2}$ between $10^{-10}-10^{-7.5}$, besides, metallogenic material source, suggested by sulfur isotopes, that convective magmatichydrothermal fluid mixed the metal components extracted from surrounding rock. Since chalcopyrite tends to chemical remobilization induced by retrograde fluid, compared with other sulfides, trace elements are easy to migrate into chalcopyrite and be enriched in. The initial mineralization process and the metamorphic evolution rules of the Hongtoushan deposit are elucidated based on the textures, trace elements, and sulfur isotopes in sulfides, which is the significance of understanding the genesis of the same type of massive sulfide deposits undergoing metamorphism. 